\title{
Exploring Mainland Chinese and Dutch High School Students' Conceptions of Learning Technology: A Phenomenographic Analysis
}

\author{
Xia Wu ${ }^{1,2}$, Jeanna S. de Haan-Topolscak ${ }^{3}$, Marc J. de Vries ${ }^{3}$, Bangping Ding ${ }^{1 *}$ \\ ${ }^{1}$ School of Education, Captial Normal University, Beijng, CHINA \\ 2 Fangshan Teachers Training College, Fangshan, Beijng, CHINA \\ ${ }^{3}$ Department of Science Education \& Communication, Delft University of Technology, Delft, the NETHERLANDS
}

Received 6 April 2020 - Accepted 3 June 2020

\begin{abstract}
The aims of the study were to investigate high school students' conceptions of learning technology (COLT) in mainland China and the Netherlands, and tried to explain the differences from different educational and social backgrounds. The phenomenographic method was used, interviewing 85 students from both counties. The findings of the research shows that COLT in this study is conceptualized as (1) learning knowledge, (2) learning technology skills, (3) learning technology methods and abilities, (4) using knowledge into practice, (5) doing research, and (6) preparing the exams and getting the credits. There are only a few differences found in the kinds of COLT between Chinese and Dutch students, and reasons behind them are explored.
\end{abstract}

Keywords: high school students, conceptions of learning technology, phenomenography, the Netherlands, mainland China

\section{INTRODUCTION}

The aims of this study were to investigate high school students' conceptions of learning technology (COLT) in mainland China and the Netherlands, and efforts were made to describe and analyze the similarities and differences, if any, between them from different educational and social backgrounds. Reviewing the literature, it was found that a number of articles indicate that there is a close relationship between conceptions of learning (COL) and approaches to learning (e.g. Chiou et al., 2012; Dart et al., 2000; Edmunds \& Richardson, 2009), and some researches demonstrate that a learning outcome of relatively high quality must be especially associated with deep-level approaches and a constructive learning conception (e.g. Tsai, 2004; Van Rossum \& Schenk, 1984). Other studies indicate that our conceptions significantly influence our perception and interpretation of events, people, and phenomena surrounding us (Pratt, 1992). The students' COL is a significant research area of in-depth study on students' learning.

There are some in-depth researches on students' COL. Säljö (1979) identified five kinds of COL, which are increasing of knowledge, memorizing, acquisitions of facts and procedures that can be retained and/or utilized in practice, abstraction of meaning, and an interpretative process aimed at the understanding of reality. Van Rossum et al. (1985) described COL as increasing of knowledge, memorizing, application of knowledge, seeking out the relationships within and between the subjects, and personal development. Marton et al. (1993) proposed six types of COL as increasing one's knowledge, memorizing, applying, understanding, seeking something in a different way, and changing as a person. Marshall et al. (1999) pointed out five types of conceptions of learning which were memorizing, applying equations and procedures, making sense of physical concepts and procedures, seeing phenomena in the world in a new way, and a change as a person. These kinds of COL are helpful to construct the category of students' COLT in our study.

Besides, some articles indicate that the students' COL is related to cultural and educational contexts, and to some extent, domain dependent (e.g. Buehl, \& Alexander, 2001; Tsai, 2004). In the area of technology education research, recent statistics (Williams, 2018) indicated that researches concerned were more focused on the areas such as curriculum, design, STEM, teaching and learning, and that less attention was paid to the 


\section{Contribution to the literature}

- The COLT can be enriched from the perspective of high school students.

- By comparing the COLT of Chinese and Dutch high school students, it can be found that the students' COLT of the two countries have much in common, and some nuances and differences between Chinese students and Dutch students in their COLT are, in our view, mainly derived from different forms of technology courses offered.

attitude area, which was more concerned about the perceptions of technology or design. Most of the attitude studies were done in the context of the Pupils' Attitude Towards Technology (PATT) project on the basis of which international conferences are regularly organized. However, the studies above are somewhat limited in that they do not directly reveal students' COLT. To do this in a comparative way is necessary and valuable, for it can give us insights into whether there might be any differences between students' COLT between culturally different countries and the reasons behind them. The interviewees in the present study were high school students from both mainland China and the Netherlands, who can provide more different insights for the existing research literature. To compare the students' COLT from two or more countries that have completely different cultural and social backgrounds can provide an empirical basis for a deeper understanding of technology teaching and learning.

For the reasons above, it is of great significance and importance, in our points of view, to study students' COLT which can provide a deeper understanding of students' conceptions of technology and technology learning, so that the students' learning can be understood more comprehensively by technology teachers and researchers. This will provide a basis for improving technology teaching and education policymaking. Because the students' COLT in each country may be different, it is necessary to research the students' COLT in the context of different countries, so as to understand the unique characteristics of technology teaching from the perspective of students, and in this way different experiences can be provided for improving on technology education. Due to the lack of research on the students' COLT, especially the comparative research on the students' COLT in different countries, this research is just to make up for the deficiency of this aspect in the literature.

\section{Contexts of High School Technology Education in Mainland China and the Netherlands}

Technology is one of the eight learning areas in high schools (grades 10-12) in mainland China. The technology curricula in high schools are divided into information technology (IT) and general technology (GT), both of which have a separate and different national curriculum standard. The GT course is designed to improve on students' core technological literacy
(CTL), with design learning and operation learning as its main features, based on practice, focusing on creativity, and embodying the unity of technology and humanities (MOE, 2017). In the newly-published Chinese General Technology Curriculum Standards for Senior High Schools (CGTCSSHS), CTL has been proposed, which consists of technology awareness, engineering thinking, innovative design, the ability of expression with patterns, and materialization (MOE, 2017). The technology curricula compared in this paper mainly refer to these making \& design curricula (e.g. GT in China and O\&O in the Netherlands, respectively).

In 2003, the first version of Chinese Technology Curriculum Standards for Senior High Schools (CTCSSHS) was published by the Ministry of Education in mainland China (IT and GT were written in two separate parts), which means all the high schools across the country must offer the GT course. In other words, GT is a required school subject for high school leavers. Under the current curriculum reforms in mainland China, in 2017, the CGTCSSHS was published. There are some changes in the course structure between the CTCSSHS and the CGTCSSHS, including a reduction of required credits (from 4 credits to 3 credits) and an increase in elective content in the CGTCSSHS. To take Beijing as an example, all the high school students have to take the GT course in at least two semesters (1 or 2 lessons each week) and to pass the high school qualification examination (HSQE) for the GT course. However, only a few high schools offer elective courses. The situation of the GT course varies in each province of China. A few provinces (for example, Zhejiang province, but not Beijing) incorporate their technology subject into the elective subjects of Gaokao or the College Entrance Examination (CEE). Some provinces do not have the provincial unified HSQE for GT, which means the credits for GT are mainly given by the school technology teachers.

In the Netherlands, Technology was introduced as a separate subject in lower secondary schools in 1993, with national standards available. In the 2000s many schools started realizing the standards not through a separate subject but through a part of science education. Meanwhile a new type of school was initiated, the socalled Technasium schools, and they have a separate subject 'Onderzoeken en Ontwerpen (O\&O, or in English: Researching and Designing), in both lower and upper secondary schools. O\&O is compulsory in lower 
secondary education, but elective in upper secondary education. Another subject that was launched in that time is Nature, Life and Technology (NLT) in upper secondary schools (also as an elective subject). Both O\&O and NLT can be seen as a Dutch type of integrated STEM education. As half of the interviewed Dutch students had O\&O experiences, some more detailed information will be presented here.

In the Netherlands, O\&O has greatly promoted the formation of students' COLT. After just fifteen years of existence, $\mathrm{O} \& \mathrm{O}$ has been broadly accepted and recognized in the Netherlands. As a Technasium education curriculum, O\&O has proved very successful, having seen a growth from just five schools to ninetyfive schools in the period from 2006 to 2017 (Vaksectie Natuur \& techniek SLO, 2017). Students follow the O\&O course from their first year to the final exams. This concept was set up by two inventive teachers. (Stichting Technasium, 2020) which focuses on developing the students' important skills, such as cooperation, entrepreneurship, creativity, communication, selfmanagement and project-based work. They founded a Technasium where the course $\mathrm{O} \& \mathrm{O}$ is taught. The core of $\mathrm{O} \& \mathrm{O}$ is to have students involved in real-life problems with a problem owner at a company or organization. Companies and institutions of all sizes are connected to secondary schools and support learning engineering through a research and design process. These companies are not necessarily involved in engineering but do need engineering support. Most of the companies appreciate unforeseen innovations suggested by students, 'a fresh angle', and invest their time in students' technological education. Therefore throughout their secondary school career, O\&O students are supported by field experts and coached by teachers in their work on authentic tasks originating from companies and various institutions. The final assignment 'Meesterproef' (in Dutch, which means final examination) also involves Polytechnic or University experts (e.g. Stichting Technasium, 2020). A major goal (Schalk \& Bruning, 2014) is, according to the program of examination, to let students get acquainted with different technological professions. Therefore, students get acquainted with different professions and issues in science and technology at an early stage. Working 8-10 weeks on design or research projects, Technasium students develop important skills, such as: cooperation, entrepreneurship,

creativity, communication, self-management and project-based work. Students always work in a team on real and current science and technical projects. As there are no textbooks for this subject for each project a unique assignment is written, together with the client, which is then used as the subject book instead. A Technasium foundation is convinced that the subject O\&O offered in the Technasium is the formula for Science, Technology, Engineering, and Mathematics (STEM) education in the secondary schools in the Netherlands.
As mentioned above, the principal aims of the study were to represent the high school students' COLT in a systematized form and to compare the students' COLT in mainland China and the Netherlands, so as to analyze the reasons for the differences identified. The research questions in this study were listed as follows:

(1) What is the high school students' COLT in mainland China?

(2) What is the high school students' COLT in The Netherlands?

(3) What are the similarities, if any, between the mainland Chinese and Dutch high school students' COLT?

(4) What are the differences, if any, between the mainland Chinese and Dutch high school students' COLT?

\section{METHODOLOGY AND METHODS}

Phenomenography is a research methodology which aims at description, analysis, and understanding of experiences, that is, research which is directed towards experiential description (Marton, 1981). A fundamental distinction is made between two perspectives in phenomenography: the first-order and second-order perspectives, which means that from the first-order perspective one aims at describing various aspects of the world, and from the second-order perspective one aims at describing people's experience of various aspects of the world (Marton, 1981). Phenomenology aims at empirically identifying the second-order perspectives or conceptions by interviewing the participants face to face. The conceptions thus gained, whether correct or not in the sense of the first-order perspective, are true and authentic in the sense of the second-order perspective, that is, they come from the hearts of the participants and are confirmed by the researchers. Therefore, what phenomenological studies try to find out can be considered as a kind of truth or authentic conceptions on the part of the participants under study. These conceptions can be organized into 'categories of description' (Marton, 1981) which are then used to create a hierarchical set of understandings which are referred to as an 'outcome space' (Marton, 1986, p.177). The outcome can thus be seen as a structured pool of ideas, conceptions, and beliefs underlying the possible interpretations (or possible constructions) of reality in question and it is enhanced steadily, as new possibilities are continually added to those previously available (Marton, 1981). These outcomes can enrich our understanding of the world. In the teaching and learning process, the conceptions held by the students may differ from those which the author of the textbook or the teacher is trying to make the students acquire. It is significant to understand various kinds of conceptions that students hold which can make the teachers better understand the students and help them improve teaching. 


\section{Participants}

In this study, 50 students came from three different high schools in Fangshan district (one of the rural districts) of Beijing, while 35 students [20 students who have chosen O\&O (N1-N20), 15 students who haven't chosen O\&O (N21-N35)] coming from the Christtelijke Lyceum Delft in The Netherlands were randomly selected. Each participant was given a code, including a letter and one number. The letters indicated his/her nationality, that is, ' $\mathrm{N}$ ' stands for the students from the Netherlands while ' $C$ ' refers to the students from mainland China.

\section{Protocol of the Interviewing}

Based on the guiding interview questions made by Marshall et al. (1999) and Tsai (2004), a protocol of the interview was designed (with questions 1,2,4,5,7) at the beginning, focusing on the open-endedness of the problem and providing the respondents with a sufficient space for answering the questions. After the interviews in China (with questions 1,2,4,5,7), some of the protocol of the interview had changed; question 5 was replaced by question 3 and 6 , that is, when interviewing the Dutch students, a modified protocol was used (with questions $1,2,3,4,6,7)$. This was due to the different contexts of technology education in China and the Netherlands. If the student being interviewed chose a technology course (such as O \& O in Holland or GT in mainland China), the 7 th question needed to be answered. If the respondents couldn't answer these questions or the answers were vague and abstract, the interviewer would ask the interviewees to describe specific learning experiences. The interview protocol was constructed with a set of interview questions, as follows:

1. Could you describe what technology is, on your own perspective?

2. What do you mean by 'learning technology'?

3. What do you like to learn about technology in school?

4. How do you know when you have learned something about technology?

5. How do you learn technology?

6. In what school subjects do you learn about technology?, what kinds of activities are used to teach you about technology?, and

7. Have you had technology lessons in primary schools (Basisschool, age 4-12) or middle schools (onderbouw van de middelbare school, maybe age 12-14)? Is there any difference between the technology lessons now and before?

\section{Data Collection and Analysis}

Based on the method of data collecting and processing in phenomenography, some processes were followed. Firstly, a face-to-face interview was conducted by the first researcher, and each student was interviewed individually. All of the individual interviews were taperecorded. The protocol and purpose of the study were introduced to the interviewees before starting the interview, and after obtaining the student's agreements the interview could be started. All students interviewed in the Netherlands have signed an agreement before the interview. Secondly, the tape-recording was transcribed into text verbatim, and some important sentences or words were marked. Thirdly, the transcribed texts were read repeatedly for several times and the data was coded accordingly. The researchers' own conceptions of learning technology needed to be suspended so as to avoid the influence of their own conceptions. The sentences and the keywords underlined and derived from the data needed to be read repeatedly so as to summarize the specific similarities and differences between students' interview data. For some keywords, more evidence was needed to explain the true meaning of these words. Taking 'research' as an example, some students described 'doing research' in the following way:

C12: Learning technology is learning and researching mechanical (products). I can understand the theory and knowledge behind them, what they look like, how they are constructed, as well as what are their characteristics.

N1: With the subject, we're doing here with the research and making new things, it's very useful to learn about technology.... it's like mostly you're basically only working in a team with likely three other people. We just work on a big project and other teachers just are there to help you and to guide you through the project.

The first kind of conceptions which was about researching a product should be categorized into 'learning knowledge through researching the products', and the second kind of conceptions which was about doing a research project should be categorized into 'doing research'. Because of different contexts, the same keywords may have different meanings.

Finally, the categories of descriptions were formed into an outcome space, consisting graphically of Figure 1 and Figure 2. The data of each interviewee was read again to rectify the outcome space.

\section{FINDINGS}

The students' COLT is conceptualized as (1) learning knowledge, (2) learning technology skills, (3) learning technology methods and abilities, (4) using knowledge into practice, (5) doing research, and (6) preparing the exams and getting the credits. Figure 1 and 2 outline the 


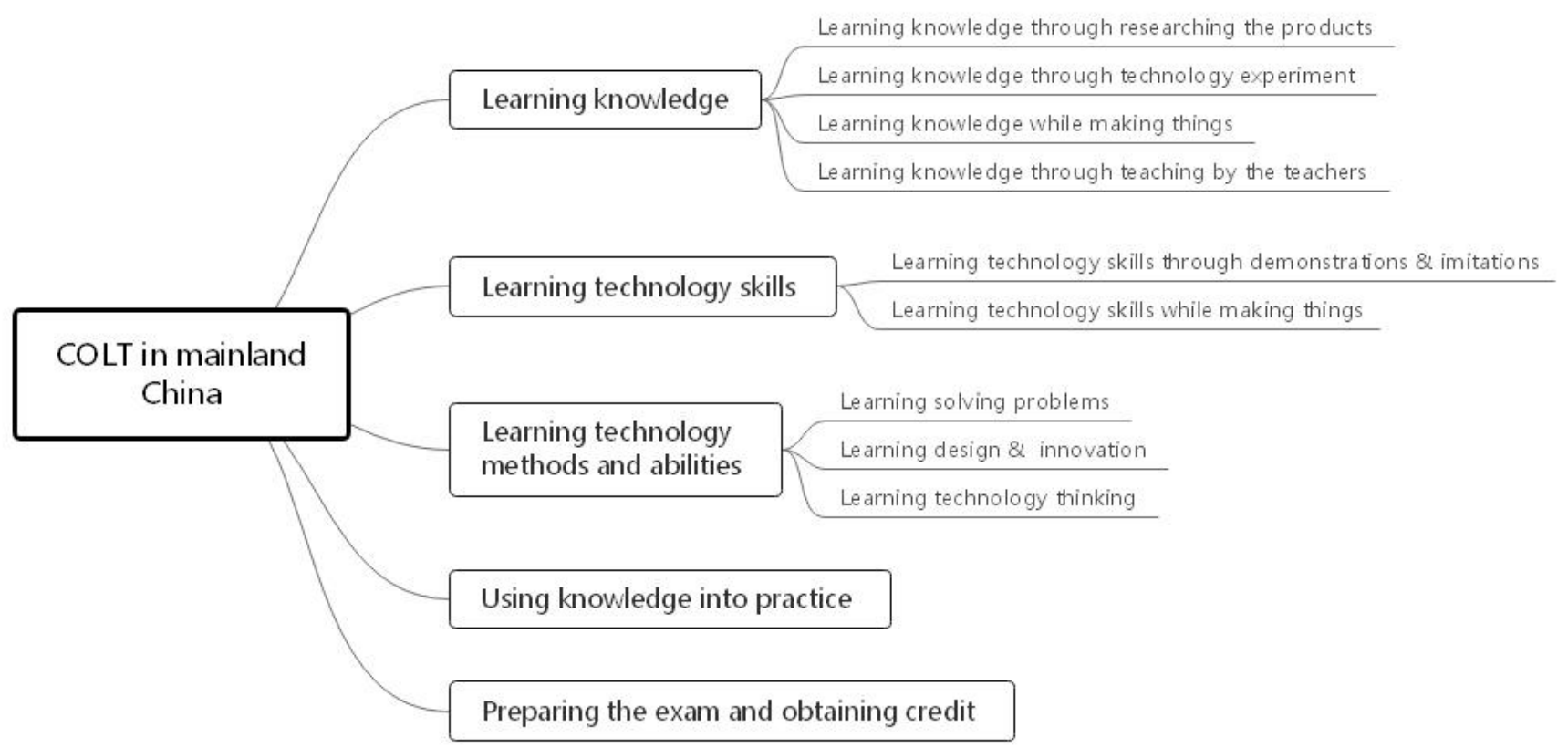

Figure 1. The students' COLT in mainland China

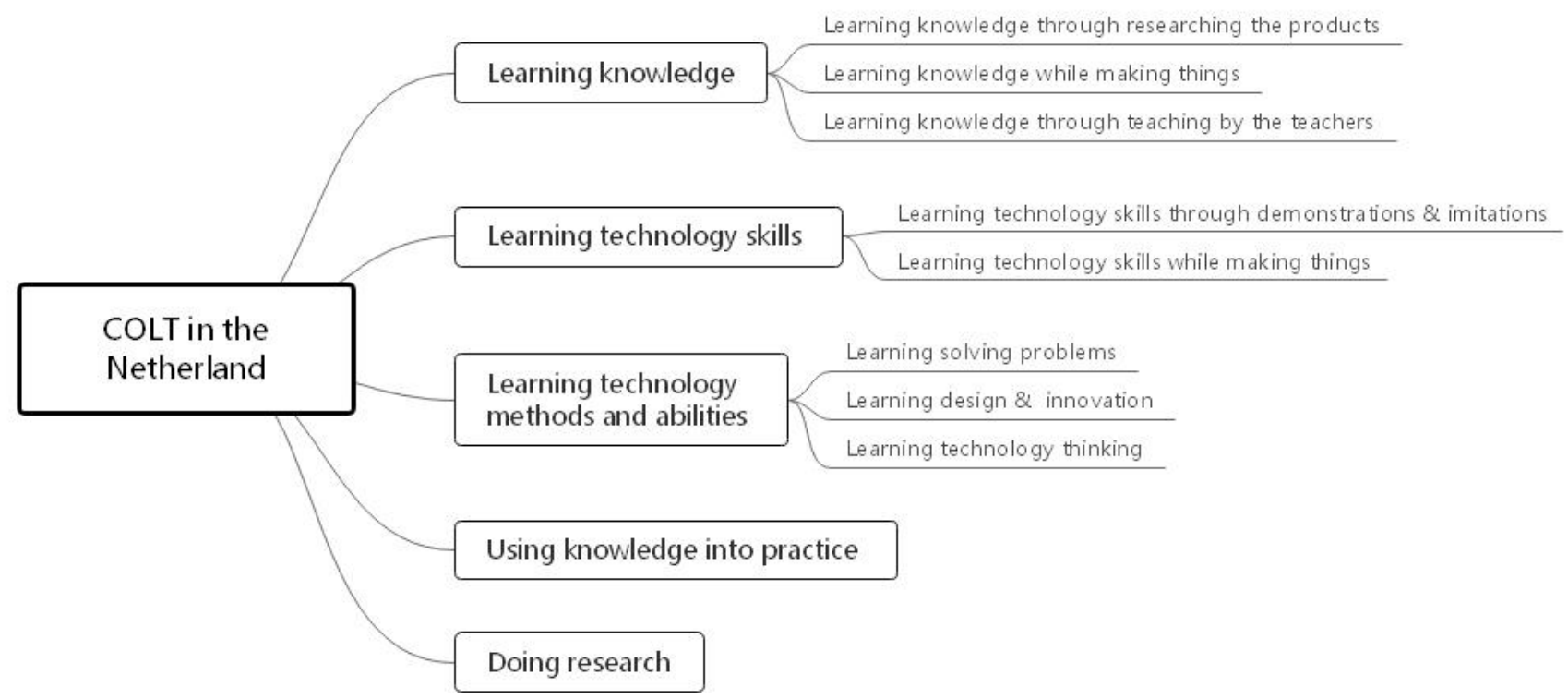

Figure 2. The students' COLT in the Netherlands

students' COLT in mainland China and the Netherlands respectively.

Contrasting the researches (Marshall et al., 1999; Marton et al., 1993; Säljö, 1979; Van Rossum et al., 1985) on students' COL above cited in the introduction section, it is obvious to see that some of the categories in them can also be found in this study, such as increasing of knowledge, application of knowledge, but others can't, such as memorizing and abstraction of meaning. Many of these results are determined by the nature of technology and the characteristics of technology learning. Most of the outcome space of the students' COL mentioned above are classified from the perspective of learning objectives and show a broader description of students' learning. However, based on the data analysis in this study, when the students were asked how they understood learning technology, many of them not only reported from the aspect of learning objectives, but also from the perspective of learning content and learning methods, and even gave many specific examples. Therefore, for specific subjects like technology, it is necessary to describe students' COLT more systematically and detail them from at least three aspects which are learning objectives, learning contents and learning methods, so as to highlight the different features of students' COL than their COLT among different subjects. From the perspective of learning objectives and learning contents, the students' COLT can be generally divided into 
learning knowledge, learning technology skills and learning technology methods and abilities. From the aspect of learning methods, the students' COLT can be described as learning while making, learning through teaching by the teachers (including demonstrations \& imitations), applying, researching, etc. As the data is gradually abstracted and clustered, various categories are combined to form the outcome space. The outcome space may not form a theory, but it can help the educators better understand the characteristics and essence of technology teaching and learning from the perspective of students, and some of the problems in technology teaching and learning can be exposed which then can help for improving technology education.

\section{Learning Knowledge}

The knowledge involved shows a broad category, including all the knowledge interrelated with technology, such as the science knowledge behind technology products, the technology knowledge, and new knowledge used to broaden one's horizons.

For example, some students describe learning technology as learning the science knowledge behind technology products. As the following students stated:

C45: First, to understand their (products') principles and production methods, how they help people, where to apply, when we see something, we may know how they work and how they are used.

N31: I think science is a start of technology. So, you have to first understand the things and understand the science behind something. And then you can progress on that and make a technology or better technology.

Some indicate that learning technology is to learn the technology knowledge, such as the design theory, criteria and specifications, practical considerations, etc. Some students, for example, described them as follows:

C19: (Learning technology) is to deliver some of the existing technologies or means to others, which includes the practical knowledge, the concepts, the technology knowledge, and some awareness of innovation.

N2: Learning technology is learning about the ins and outs of technology. Not only what it does for humans, but also how it works and which component something has and why the makers of the product choose the components they chose. Maybe it's for economic reasons, or maybe it's for safety reasons. So, the incident [produces] not only how it looks on the outside, but also what it's made of, and why it's made of, the components that are made of.

Some believe that learning technology is to know more new knowledge used to broaden one's horizons. The following students indicated that:

C30: I think if there are conditions available, teachers should show students more interesting things. I don't think the knowledge in the textbooks is much important. What's important is to broaden your horizons.

N31: (do you mean in the classes you want to learn more new technologies from the teachers?) That will be better, because technology is a huge part of our sight and we should know a lot more about it. I don't get many lessons about technology in the school.

Many students can realize that technology has a unique knowledge of its own through learning technology, which is quite different from science knowledge. The process of learning technology includes learning technology knowledge, science knowledge, and various interdisciplinary knowledge. Some students argue that the purpose of technology education in high schools is to know as much knowledge related to technology as possible, in order to broaden their horizons. More attention should be paid to the universality of technology than the specialization of technology. The point here is that there are nuances in students' understanding of knowledge. In addition, based on different learning methods, students' COLT can be further categorized as (1) Learning knowledge through researching the products, (2) Learning knowledge through technology experiment, (3) Learning knowledge while making things, and (4) Learning knowledge through teaching by the teachers (see Figures 1 and 2), as detailed below.

\section{Learning knowledge through researching the products}

Students who hold this conception believe that the process of learning technology is that of learning knowledge through researching the products, which means that the relevant knowledge and technology experience are learnt by disassembling and researching technology products. For example, the following students stated that:

C12: Learning technology is to learn mechanical products. I can understand the principle, as well as what they look like and what their characteristics are. 
N5: (Learning technology is) to learn to understand how the phone works, or how a computer works.

This kind of students' COLT frequently appears in the interpretation of the term 'learning technology', but it is less revealed in describing the actual technology learning process.

\section{Learning knowledge through technology experiment}

Students sticking to this conception believed that learning technology is learning knowledge through technology experiment, which is similar to the phrase technology test. Technology experiment can be understood as the process of detecting the performance of an object. For example, these students were of the opinion that:

C47: There are some things in the textbooks that can be operated, and we can do some practice like doing some technology experiments guided by the teachers.

C48: For example, how many legs of the table are more stable? How to make the table more stable? Let's try all kinds of ways, maybe it will be better.

This learning conception is only found in Chinese students' COLT. There are also some Dutch students who are inclined to think that the technology can be learned from experiments, but these experiments mentioned are science experiments. The conception seems to demonstrate that some Dutch students confuse science experiments with technology experiments. For example, one student offered the ideas as follows:

N23: (What kinds of activities are used to teach you about technology?) Sometimes in physics class they (the teachers) give us a board, and then some wires can connect the wires (and electronic components) together, and then let the light bulb light up. In chemistry class, once we made lemon juice, and then put the flakes in the lemon juice, and it could conduct electricity. I can think of this as learning technology.

\section{Learning knowledge while making things}

Another conception that the students hold is that learning technology is learning knowledge while making things. This kind of learning conception is consistent with Dewey and Dewey's (1915/1980) experience learning theory, which is focused on learning by doing. For example, some students offered their ideas as follows:
C19: If you are in class, you should listen to the teacher first, and then do it yourself. I'm more inclined to know what I want to know while I'm doing it.

N5: The teachers teach you that you have to find a thing to yourself by researching on the internet. For example, you check 'how do I make this wheel spin?', and you search that for yourself, and then (you know) how to make the wheel spin. And then you create different parts of the robots, which need to do different things.

\section{Learning knowledge through teaching by the teachers}

The fourth conception that the students hold is that learning technology is learning knowledge through teaching by the teachers. Most of the Chinese students highlight the importance of learning technology knowledge in the interview. Many students both in China and in the Netherlands who did not choose O\&O expressed that learning knowledge through teaching by the teachers was preferred. Some students offered their ideas as follows:

C25: The teacher may teach you something about technology theory. We can understand the nature of the things from a theoretical perspective. I think this is most important. For example, before hands-on practice, the teachers should teach the theories first, the students should practice on the basis of understanding. I think the effect would be better. We should make something consciously, not blindly.

N30: So I don't have the interest to learn it myself. So I need someone else to guide me, when I learn about technology and more science behind it.

\section{Learning Technology Skills}

The conception that learning technology is learning technology skills is another kind of conception widely existing among students in both countries. The technology skills refer to two types, which are life skills and professional skills. The life skills include the use of common tools and daily products in life, such as repairing furniture with hand tools, changing bulbs, using digital cameras, while the professional technology skills are more used in design or industrial processing, such as welding technology, metal working technology, 3D printing technology, and laser cutting technology. Different students demonstrate their different ideas as follows: 
C5: (Learning technology is) to learn some skills you will use in your daily life, to improve one's ability, and the abilities for living.

N20: So you can learn to program or something else, or work with the newer type of machines, like a 3D printer.

Learning technology skills is a unique feature that distinguishes technology education from other disciplines. From different learning methods, two types of students' COLT are found as (1) learning technology skills through demonstrations \& imitations, and (2) learning technology skills while making things.

\section{Learning technology skills through demonstrations $\mathcal{E}$ imitations}

This conception that emerges from our data is that learning technology is learning technology skills through demonstrations \& imitations. This is a traditional way of learning technology that is based on apprenticeship. Some students expressed their understanding in such ways:

C9: (The teachers will) not let us learn something very deep, just learn something you can understand, such as electricity or woodwork, which are simple technologies. In class, the teacher first demonstrates and explains. If you can master and do it yourself, you learn it.

N26: We sit behind a computer and they (the teachers) tell us what to do, for example, in Excel with the crafts. So no other specific activities, actually.

\section{Learning technology skills while making things}

As to this kind of conception, the students believe that learning technology is learning technology skills while making things. These skills are generally not taught by teachers, but practically improved in the process of technology design and production by students themselves. The following statements, for example, express the students' conceptions of this kind:

C25: It depends on what I want to do, and then I see if I have the relative technologies. If I don't have these technologies, I need to learn them in order to achieve the goal.

N15: Maybe some started with a week of workshops, just designing and printing something on your own. So you can use that skill later in designing, which can really help.

\section{Learning Technology Methods and Abilities}

A large number of students in question conceive of learning technology as learning technology methods and abilities which involves the CTL, including the ability to find out and solve problems, the ability to comprehensively use knowledge, the ability to model and evaluate products, the ability of systems thinking, and innovation ability, etc. These conceptions can be found among the students both in China and the Netherlands. The specific categories can be divided into (1) learning to solve problems, (2) learning design \& innovation, and (3) learning technology thinking.

\section{Learning to solve problems}

Students who stated this conception believe that learning technology is learning to solve problems generally based on the real world. The process of learning technology is the process of problem discovering and resolving. Two students made the following statements that, more or less, emphasized problem solving in their COLT:

C24: I don't think learning technology should be limited to textbooks or some big concepts. It should start with small daily problems and then gradually develop into big problems. (We can) solve small problems, find the commonalities of these problems, learn the relevant knowledge, and then solve other problems by ourselves. During the process of solving these problems, the teachers need to give us some guidance, including some methods, such as systems method, and some optimized methods to solve problems. We can compare the optimized methods with the methods in the textbooks to find out if there are some better ways to improve.

N5: The teacher is at this time not really a teacher. She/he is more of someone you can negotiate with. But the projects we have to do by ourselves. So we go to a company, they have a problem, and we try to solve that problem and the teachers are here to guide us in the right direction. But we have to do it ourselves to research our ideas. Everything has to be done by ourselves.

It is found in some interviews that some Dutch students seem to confuse the concepts of solving technology problems with solving science problems, which means they comprehend solving math, physics, and chemistry problems as learning technology. For example, one Dutch student indicated his conceptions as follows: 
N34: (What kinds of activities are used to teach you about technology?) We had a period in which we learned a lot of things about radio waves. They (the teachers) taught us the theory behind it. And then they also gave us formulas. Afterwards, we had to solve problems with those formulas. We discussed some of those problems afterwards in class, and the information was a bit more applied to the real world. So with the subject radio waves, they also discussed radio waves in medical technology, such as scanning technology. And we didn't solve problems with it, but we still, on a basic level, got explained how it works.

\section{Learning design $\mathcal{E}$ innovation}

Within the CGTCSSHS in China, innovative design (MOE, 2017) is thought of as a series of problem-solving processes that involves innovative project brainstorming based on technology issues. Students are required to be able to collect relevant information on the basis of identifying and clarifying problems, to use humanmachine relations and related theories to conduct a comprehensive analysis, and then to propose creative and innovative projects that conform to design principles. They are also asked to carry out practical operations, including technology experiments which accord with technology performance and indicators, and technology inquiries, etc. They should be able to observe, record and analyze these practical operations accurately. They are expected to comprehensively evaluate the design plans through various social and cultural factors in order to optimize the design. Problem solving is closely related to innovative design, which means the problem is often solved by innovative design; in other words, the process of problem solving is the process of innovative design. Some students revealed their conceptions as follows:

C22: If I can use it, I think I have learned, for example, 3D printing technology. After I have learned $3 \mathrm{D}$ printing technology by myself, I have an understanding of this, and I can use these technologies to design something, complete works, and apply it to production practice.

C40: Can I understand it (learning technology) as innovation? Learning technology is to innovate. In fact, innovation is to enrich people's daily lives. The satisfaction of human beings for material needs and the progress of society are the fundamental requirements of technology.

N27: When you're able to design something or make something work on its own, I know
I've learned something about technology. I've been able to design something or do something with it.

N4: We're learning technologies, learning about computers and materials that are relative. I have to make a report of it or something else. You design something with computers and materials and you design a product. I'd like to design something, to make something, but especially about energy and how you can program computers to use energy in the right way.

\section{Learning technology thinking}

Students sticking to this conception believe that learning technology is learning technology thinking, that is, a kind of engineering thinking or systems thinking. In the CGTCSSHS in China, engineering thinking (MOE, 2017) is described as a kind of planning thinking with systems analysis and comparison as its core. The students are required to be able to recognize the diversity and complexity of systems and engineering; to use systems analysis methods to conduct factor analysis and overall planning for problems in a specific technology domain; and to use simulation and simple modeling to design. They are also asked to recognize and use basic conceptions and methods of structures, processes, systems, and controls. They should be capable of conducting simple risk assessments and making comprehensive decisions. The statements that involve such COLT are as follows:

C29: Learning technology is learning methods. For example, someone developed this product based on some technologies. How did he/she come up with it? How is it created and how is it applied? How to promote? They (these methods) can be understood as technology thinking.

N4: It is just there to think in a way in which you can find solutions easily.

\section{Using Knowledge into Practice}

Students who embraced this conception believe that learning technology is using knowledge into practice. The students' COLT in this conception demonstrates learning technology as a process of applying knowledge. There are also a considerable number of students who further understand learning technology as using science knowledge into practice. Some students indicated their conceptions as follows:

C17: Learning technology is something practical; the knowledge of physics lessons, for example, can be used in technology lessons, 
for instance, making a small desk lamp. I have learnt the voltage, current, bulbs, and switches in physics lessons, and these can guide me to make a lamp in technology lessons.

N21: I think like when you learn about technology and then you've actually learned it when you can also use it yourself. Like your father says, this is how you use the editing program. And then after a while practicing, you actually can use it to news for something good and make good projects with it. Then you've learned, it's like when you can also put it to something, not just theoretically, but also in practice.

\section{Preparing the Exams and Getting the Credits}

Students who insisted on this conception believe that learning technology is preparing for the exams and getting the credits. This conception is found only in Chinese students. For instance, two Chinese students indicated their conceptions as follows:

C17: I had labor-technical lessons in the junior secondary school. I didn't go to the high school at that time. I expected that GT courses would definitely be different, but later I found that there was no difference, and I didn't learn anything. I am not interested in this lesson at the moment. I just learn this to get the credits.

C1: At the beginning we studied the textbook. The teacher taught us, and then we learnt the textbook by ourselves. The main learning process was to learn the knowledge. That means I can answer the questions when someone asks me related knowledge after I have learned them (sic). There would be a pen-and-paper test in the last lesson (for practice and review, preparing for the HSQE).

\section{Doing Research}

Some students in the Netherlands demonstrated their COLT as doing research generally based on a research project. The project indicates some characteristics: the projects are based on real problems of daily life, the knowledge involved is usually interdisciplinary, students need to do research or design to solve the problems in the form of groups, and the teachers play the role of mentors and advisors rather than just managing students' learning. For example, the STEM courses are research-based learning lessons. This conception is found only in Dutch students, not in
Chinese students. Some Dutch students revealed their conceptions as follows:

N2: We learn to develop new products and do research, as this subject is not for everyone who could choose to follow this, but everyone has to do some research for school. At some point by doing research, you learn the basics of technology and how the world works. And the technology is used to add something to the world. And if you can't understand how the world works in the first place, you can't understand anything about technology.

N5: We need to do research about some kind of technology and the newest research and write something about it. Or sometimes you may use new technologies, like we have to code a robot for more robots for ourselves.

\section{DISCUSSION}

\section{The Students' COLT has Become Enriched in both China and the Netherlands}

Through the data analysis, it is found that the conceptions of learning technology (COLT) for both Chinese and Dutch students have much in common, such as considering learning technology as learning knowledge, learning technology skills, learning technology methods and abilities, using knowledge into practice. In the context of technology education reforms, the students' COLT in both China and the Netherlands is enriched as design \& innovation, problem solving, and technology thinking. In China, the concept 'core technological literacy'(CTL) has been proposed by MOE (2017) and has been constructed specifically as CGTCSSHS. With the in-service teacher training programs in place and the improved educational environment in mainland China recently, technology teachers' conceptions of teaching technology have changed gradually. For example, more attention is paid to cultivating students' CTL, such as design \& innovation, craftsmanship, systems thinking, the abilities of solving problems, collaboration, and an increasing number of new methods of technology teaching are being used, including project-based learning, problem-based learning, design-based learning, etc. As a result, the students' COLT has become reasonably richer accordingly.

What needs to be seen at the same time is that even if the students' COLT in both countries has seen changes tremendously, there are still a certain number of students who are confused about some concepts of science and technology, and there are a considerable number of students who have limited COLT. 
The Narrowness of Students' Conceptions of Technology (COT) has Led to the Narrowness of Students' COLT

Some of the students' COT is limited, which may deeply affect their COLT. Firstly, only a few students focused on the human characteristics of technology. In all the interview data, nearly most of the students in the Netherlands described technology as artifacts, skills, technical methods, and technical processes. Only a few students mentioned the humanistic characteristics of technology, including the history of technology, the relationship between technology, society, and nature, the impact of technology, and the ethics of technology, etc. Even with the constant probing of interviewers, only several Dutch students indicated that they had learned technology from other subjects, such as humanities or arts. Because the third and fifth questions in the interview protocol were newly added after interviewing the Chinese students, this phenomenon is not surfaced in the Chinese students' interview data. Mitcham (1994) indicates that philosophy of technology has always had two philosophical traditions, one from the engineering tradition of technology, which tends to be more protechnology and analytic, and the other from the humanities tradition of technology, which tends to be more critical and interpretative. He also mentions many famous philosophers' discussions on the human characteristics of technology, such as Mumford, Ortega, Heidegger, which touch on the relationship between technology, nature and society, and the humanistic nature of technology, etc. Four types of technology, that is, technology as object, technology as knowledge, technology as activity, and technology as volition, are demonstrated in Mithcham (1994). Volition profoundly reveals the essence of technology, that is, technology is the embodiment of human will and the free display of human spirit. In the 1990s, philosophy of technology went through what was called an empirical turn, and in 2016, Kroes and Meijers proposed an axiological turn, which is concerned with values (de Vries, 2018). These changes indicate a deepening understanding of technology that also needs to be followed by technology education researchers. In the CTL proposed by MOE (2017) in China, technology awareness is the first to be explained which is considered to be the perception and experiencing of technology phenomena and technology problems. Students can form the basic conceptions of the man-made world and the relationship between technology and human beings; have an awareness of technological specifications, standards, and patent; make a rational analysis of the impact of a certain technology on human beings, society and the environment; raise the consciousness of safety and responsibility of technology and the awareness of ecological civilization and environmental protection; promote the awareness of technology ethics and morals; grasp nature of technology; understand the organic relationship between technology and human civilization; and not least form the understanding of, and active adaptation to, technological culture. Based on the students' answers, the cultivation of students' technology awareness should be strengthened.

On the other hand, there are a large number of students in both China and the Netherlands who believe that learning technology is using science knowledge into practice, which also shows limited COT. Mitcham (1994) indicates that there have been distinctive arguments against Bunge's epistemology of technology as applied science in the history of philosophy of technology. During the process of technology practice, it is not sufficient only to be supported by science knowledge; more needs to be required to solve comprehensive problems in technology, such as designing and innovating, which is composed of technology knowledge, technology skills, and technology capabilities and methods, etc. Technology researchers have been struggling to find technology knowledge to firmly establish the ontology of technological philosophy. Vincenti (1990) points out that technology knowledge utilizes problematic data that is different from scientific data, and identifies six categories of notable engineering knowledge. Meijers and de Vries (2009) list four possible characteristics of technological knowledge. And Gu (2018), a Chinese educator of technology education, proposes that technology education should pay special attention to technology knowledge with methodological significance. The conception of using knowledge into practice is consistent with the previous research results of the students' COL (Marshall et al., 1999; Marton et al., 1993; Säljö, 1979; Van Rossum et al., 1985). It is of great significance that the unique technology knowledge, methods and abilities should be learned by the students.

Secondly, the students who had not participated in $\mathrm{O} \& \mathrm{O}$ in the Netherlands only mentioned design \& innovation as technology methods and abilities, but didn't pay attention to other technology methods and abilities, such as problem solving and systems thinking. Technology education focuses on design, research, and problem solving whereby many advanced core literacies can be developed in the process of design and making, such as problem solving ability, systems thinking, critical thinking, innovation ability, modeling ability, and cooperative or collaborative ability. Compared with other subjects such as the language arts and mathematics, the advantages of technology as a school subject become obvious, and technology education should be a necessary part of the learning areas in high school. However, in the interviews, many Dutch students who hadn't chosen O\&O believed they hadn't learned anything about technology at school. 


\section{A Confusion between Science and Technology has been Identified}

There are a certain number of students who are confused about science and technology, for example, the concepts of science and technology, science experiments and technology experiments, and problem solving in science and technology.

In the first place, science is to discover the laws of nature or put forward theories about nature, which answers the questions of 'what is it' and 'why is it'. Technology uses the laws of nature to change it for human needs and wants, which answers the questions of 'what to do' and 'how to do it'. Zwart (2009) indicates that modeling in engineering is different from modeling in natural science, which means that in natural sciences, models only aim at playing a role in developing knowledge about reality, whereas the purpose of modeling in engineering is to develop new artifacts and systems.

In the second place, the scientific experiment in the educational area is a clear and specific operation or activity to test a certain scientific theory or hypothesis, which focuses on the verifiability and repeatability of the experiment, such as the classical experiment to verify Newton's three laws. In contrast, the technology experiment in the educational area is an activity to understand the result of something or the performance of something generally for the purpose of exploration, that is, a tentative operation is carried out and the result will be unknown, such as testing the strength of wood with different cross-section shapes.

Finally, from an educational perspective, problem solving in science is more about explaining scientific phenomena with scientific experiments or equation \& calculations. Problem solving in technology, in contrast, refers to the use of multiple knowledge and capabilities to solve problems in real life that may be more sophisticated. Although modern science and technology are closely related, students should be able to distinguish between some basic concepts of science and technology after they have finished their technology courses.

Compared with Chinese students, Dutch students seem more confused about the concepts related to science and technology, which may be due to the fact that Chinese students have a more systematic learning of the technology courses than their counterparts in the Netherlands.

\section{The Students' COLT has been Reflected in Learning Content and Learning Methods}

Other differences in the students' COLT in China and the Netherlands can also be summarized here. The Chinese students' COLT is more focused on learning technology methods, abilities as well as knowledge. Under the category of learning technology as learning knowledge, the number of students who expressed their willingness to learn knowledge through teaching by the teachers was the largest. As compared with the Chinese students, the Dutch students' COLT is more focused on learning technology methods, abilities and skills. More than half of the Dutch interviewees pointed to learning technology as learning design and innovation. Learning technology as preparing the exams and getting the credits can be found only in the Chinese students' COLT, while some Dutch students believe learning technology is doing research, which can't be revealed in the Chinese students' COLT.

From the data available, compared with the Dutch students, more Chinese students described their COLT as learning technology through teaching technology knowledge by the teachers. In mainland China, there are several versions of GT textbooks and teacher guidance books that accompany these textbooks. The textbooks need to be designed according to the CGTCSSHS which contains a lot of basic knowledge of technology, such as the definition of technology, principles and processes of technical design, technology experiments, engineering drawing, structure \& design, systems \& design, and contains a large number of technological application cases and technology experiments. In order to transfer technology knowledge to the students more efficiently or help them prepare for the HSQE and CEE exams, many teachers in mainland China choose to teach the knowledge in the textbooks. Influenced by the Chinese traditional teaching methods in the classrooms, teachers and students seem to be more inclined to teach and learn technology by classroom instruction. Of course, there are still some students who want to expand their horizons from knowing some technology cases illustrated by their teachers. In either case, the students' learning is more likely passively accepted, that is, the students' learning is more dependent on teachers' instruction. Although more Chinese students recognize learning technology as learning technology methods and abilities, it shouldn't be ignored that a considerable number of students still believe that learning technology is to learn knowledge through teachers. Another revealed problem is that some Chinese students indicate that they participate in the GT course just because they need to pass the exam and get the credits. According to the needs and interests of the students, more flexible technology contents should be developed, and various learning styles suitable for students should be provided.

From the perspective of Dutch students, some of them believe learning technology is doing research, which isn't found in the Chinese students' COLT. Many Dutch students state that all the knowledge and skills are learnt during the process of doing research by themselves, and the teachers offer help only when they are asked to do so. The formation of the COLT is closely related to the O\&O courses offered by the school from which the interviewed students came. In the O\&O courses, the students are exposed to real-life problems 
with a problem owner at a company or organization, where the students work for about 8-10 weeks in teams on real-life design or research problems and current science and technical projects. With $\mathrm{O} \& \mathrm{O}$, students have gradually formed the thinking and habit of doing research in their minds. However, the interview still identified some problems, such as Dutch students' confusion between concepts of science and technology, which may be due to their lack of systematic learning of technology knowledge.

In technology teaching, the learning contexts that need to be similar to the Engineers' real working contexts should be created by the teacher. Collin (2002) develops the engineers' conceptions of learning at work which include six categories of descriptions: learning through doing the work itself, learning through cooperation and interaction with colleagues, learning through the evaluation of work experience, learning through taking over something new, learning through formal education, and learning from extra work contexts. The students' technology knowledge, skills and abilities should be accumulated constantly through self-study, cooperative learning with others, and reflective learning in the process of researching, making, designing, and innovating.

\section{There are Different Emphases on Learning Life Skills vs. Professional Skills}

Some students in this study indicated learning technology as learning technology skills, including professional skills and life skills, which are different from the technology skills described in the CGTCSSHS. The technology skills indicated in the CGTCSSHS refer more to professional technology skills, and are closely related to the ability of expression with patterns and materialization shown in the CTL. The ability of expression with patterns (MOE, 2017) refers to the use of graphic forms to visually describe and communicate technology objects that exist in the mind or are out there objectively. The students can read common technology drawings such as simple machining drawings and control block diagrams, analyze the pattern characteristics of technology objects, and draw simple technology drawings manually or using 2D\&3D design software. Design ideas can be expressed by drawings, and the transformation of tangible and intangible, abstract and concrete thinking can be realized by technology language. Materialization (MOE, 2017) refers to the ability to use a certain technological method to convert ideas and solutions into useful items, or the ability to transform and optimize existing items. Students can know the properties of common materials and tools and how to use basic equipment, understand some common technological methods, and form a certain accumulation of operating experience and perceptions. According to the requirements of design solutions, the students can choose materials, do technology experiments, plan the process, choose and correctly use the tools, and make products. The making, assembling and testing of the products or models can be completed independently, that is, the students need to have strong hands-on practical ability and creative ability. At last, the unique role of the craftsmanship in the quality of technology manufacturing should be understood, and meanwhile rigorous attitudes of improving and pursuing excellence need to be formed.

In order to fulfill the requirements of the CGTCSSHS and the corresponding textbooks, more and more Chinese technology teachers are now willing to teach professional technology skills. However, some students expressed the view that they would like to learn more life skills, such as changing light bulbs, raising flowers, repairing broken furniture, using digital cameras, and some of them indicated that it's a waste of time to learn professional technology skills that are too difficult to learn and will not be used again in the future. Given this, the needs of different groups of students should be taken into account when setting up technology courses.

In the Netherlands, some students in our study indicated that teachers should systematically teach them the professional technology skills, for instance, how to use laser engraving machines. They complained that their teachers only offered some help when the students asked for it, and most of the technology skills were learned by themselves (self-taught), which they felt quite difficult. Learning technology skills-- quite different from learning knowledge-- is a significant aspect of learning technology, and the contents and methods of learning technology skills need to be seriously considered.

\section{Researching the Products \& Doing the Technology Experiment should be Strengthened}

Doing technology experiments and researching technology products are also important ways to acquire technology knowledge and experience, among other things. Many students both in the Netherlands and in mainland China pointed out that learning technology was researching the products, and a learning activity that the Chinese students indicate frequently is to do technology experiments in learning technology. Yet, both kinds of these activities are less mentioned in describing the actual technology learning process.

Through many years of classroom observation in Chinese technology classes, it is found by the first author that the general teaching forms of technology in primary and secondary schools are mostly focused on knowledge learning and/or skill training. After mastering the basic technology knowledge and operation skills, students are usually asked to design and make products directly without doing necessary technology research and experiments. Due to the lack of sufficient design experience, the innovation of the students' design and 
products is always limited. However, throughout the reform of technology education in the world, both technology research and technology experiment play an increasingly essential role in the technology education. The K-12 technology education in the United States (Guan, 2012), for example, emphasizes technology exploration, technology design and technology experiment, and is carried out in the form of projectbased teaching. French high school technology curriculum (Zhou, 2007) advocates a complete practical process, which means the practical activities are not only hands-on operations, but also the whole technology process of technical structure research, principle analysis, process analysis, technical design, etc. Mao (2013) demonstrates that the British national curriculum standard for technology education stipulates that students should be able to improve their product analysis ability, analyze and test the design and production of their own and others' products through technology education. Therefore, it is of great significance to strengthen the technology research and technology experiment in the technology education.

\section{CONCLUSION AND IMPLICATIONS}

Although the students' COLT in both China and the Netherlands has much in common, this study has also found some nuances and differences between Chinese students and Dutch students in their COLT, which are, in our view, mainly derived from different forms of technology courses offered. In China's case, technology education is based on the CGTCSSHS and formal textbooks, with a considerable number of teachers giving technology courses by teaching knowledge to and training skills in their students. In the $O$ \& $O$ courses offered by Dutch high schools, in contrast, students spend much of their time in solving practical problems in situ in the companies by doing research, which means more flexible learning processes and open results. Since most school subjects both in Chinese and Dutch high schools are textbook driven (except for O\&O), our agreed-upon point of view is that the differences between the two groups are not mainly due to cultural and social differences. The issues that need to be studied further in the future include the students' real changes in the core literacy and/or CTL under the two kinds of curriculum regimes, and whether the $\mathrm{O} \& \mathrm{O}$ course is suitable for Chinese high school students in mainland China. To give an anecdotal impression of the possibility that $\mathrm{O} \& \mathrm{O}$ might work equally well in China, we will finish with an experience that one of us (Jeanna de Haan) had in China when teaching a typical O\&O-lesson.

An international symposium on Technology Education took place in Beijing, in late October, 2019. In the context of a symposium on Technology Education, organized by Capital Normal University in Beijing, teacher R\&D S. (Jeanna) de Haan-Topolscak gave an example R\&D lesson at a Chinese high school. As we know, China is developing rapidly. In particular, the shift from "made in China" to "created in China" is at full speed. This was also visible in the field of education. The utilities of High school in Beijing where the lesson took place were in general comparable to the high school in Holland. Only a large sports field near the school and the number of students per class were striking for Dutch teachers. Indeed, there are 40 students per class who wear a different color sport outfit per grade. In the presence of around 50 teachers from different parts of China and other parts of the world (from Japan, South Korea, and the USA) an English spoken R\&D lesson was conducted. Despite a present interpreter and a bilingual instruction in PowerPoint, communication was complicated but nevertheless successful. The performed lesson is designed for start-up of subject $R \& D$ for approximately 24 students in Holland. Students were asked to design an amusement park island in teams of four. Main goals of the lesson improving mutual cooperation, creativity, communication and selfmanagement. Already mentioned lesson goals were supposed to be achieved through assignments based on shared ownership and intrinsic motivation. Those are desirable skills of the digital era. Despite seemingly large cultural differences and language barrier between Asia and Europe, the atmosphere in the classroom and the actions of the pupils during a lesson were very recognizable and similar to Dutch students of the same age and $R \& D$ experience. The students responded to the questions and assignment in the same way as Dutch students do. Even products were comparable. The students were also open and quite frank in feedback and criticism just like Dutch students. This lesson was conducted in almost the same classroom conditions and materials as in the Netherlands, with the same amount of the students, same assignment, duration and the performing teacher resulting in the same student actions, products and atmosphere just like in Holland. Only noticeable differences were inspiration sources of students due to social context. Of course this is only one experience and no general conclusions can be drawn from it. It suggests, however, that the differences we found between Chinese and Dutch students have their background more in curriculum differences than in cultural differences.

With the reform and development of technology education, students' COLT can be constantly enriched. The study of students' COLT is found to be a significant foundation for the study of the theory and practice of technology education, and each dimension of COLT has its unique educative value. It's of great importance and significance to understand students' COLT, because not only students are the main subjects of education, but also education researchers can further improve technology teaching according to students' needs. Thus, we suggest that it is important that the reform of technology 
education in primary and secondary schools can be promoted by the research on the students' COLT.

\section{REFERENCES}

Buehl, M. M., \& Alexander, P. A. (2001). Beliefs about academic knowledge. Educational Psychology Review, 13(4), 385-418. https://doi.org/10.1023/ A:1011917914756

Chiou, G. L., Liang, J. C., \& Tsai, C. C. (2012). Undergraduate students' conceptions of and approaches to learning in biology: A study of their structural models and gender differences. International Journal of Science Education, 34(2), 167195. https://doi.org/10.1080/09500693.2011.558 131

Collin, K. (2002). Development engineers' conceptions of learning at work. Studies in continuing education, 24(2), 133-152. https://doi.org/10.1080/0158037 022000020956

Dart, B. C., Burnett, P. C., Purdie, N., Boulton-Lewis, G., Campbell, J., \& Smith, D. (2000). Students' conceptions of learning, the classroom environment, and approaches to learning. The Journal of Educational Research, 93(4), 262-270. https:/ / doi.org/10.1080/00220670009598715

De Vries, M. J. (2018). Philosophy of Technology: Themes and Topics. In M. de Vries (eds.), Handbook of Technology Education. Cham, Switerzland: Springer International Publishing. https:/ / doi.org/10.1007/978-3-319-44687-5_1

Dewey, J. \& Dewey, E. (1915/1980). Schools of tomorrow. In J. A. Boydston (Ed.). John Dewey: The middle works (1899-1924) volume 8 (pp.1-402). Carbondale: Southern Illinoise Press.

Edmunds, R., \& Richardson, J. T. (2009). Conceptions of learning, approaches to studying and personal development in UK higher education. British Journal of Educational Psychology, 79(2), 295-309. https:// doi.org/10.1348/000709908X368866

$\mathrm{Gu}$, J. (2018). The Modern Dimension of Technology and Educational Values [in Chinese]. Journal of East China Normal University (Educational Sciences), 36(06), 10.

Guan, G. (2012). K-12 technology education in the United States: background, current situation and Enlightenment [in Chinese]. Foreign primary and secondary education, 09, 16-22.

Mao, G. (2013). The characteristics and Enlightenment of 'design and technology' Curriculum in British secondary schools [in Chinese]. Contemporary Education Science, 12, 17-19.

Marshall, D., Summer, M., \& Woolnough, B. (1999). Students' conceptions of learning in an engineering context. Higher education, 38(3), 291-309. https:/ / doi.org/10.1023/A:1003866607873

Marton F. (1986). Phenomenography-A Research Approach to Investigating Different Understandings of Reality. Journal of Thought, 21(3), 28-49. https:/ / doi.org/10.1007/BF00132516

Marton, F. (1981). Phenomenography-describing conceptions of the world around us. Instructional science, 10(2), 177-200.

Marton, F., Dall' Alba, G., \& Beaty, E. (1993). Conceptions of learning. International journal of educational research, 19(3), 277-300. https://doi.org/10.1002/ 9781444310795.ch11

Meijers, A. W. M., \& de Vries, M. J. (2009). Technological knowledge. In J. K. Berg Olsen, S. A. Pedersen, \& V. F. Hendricks (Eds.), A companion to the philosophy of technology (pp. 70-74). Chichester: Wiley-Blackwell.

Ministry of Education of the People's Republic of China (MOE). (2017). Technology curriculum standard for senior high schools. Beijing: People's Education Press.

Mitcham, C. (1994). Thinking through Technology: The Path between Engineering and Philosophy. Chicago: The University of Chicago Press.

Pratt, D. D. (1992). Conceptions of teaching. Adult education quarterly, 42(4), 203-220. https:/ / doi.org/ $10.1177 / 074171369204200401$

Säljö, R. (1979). Learning in the Learner's Perspective 1. Some Commonsense Conceptions. Gothenburg: Institute of Education, University of Gothenburg.

Schalk, H., \& Bruning, L. (2014). Handreiking schoolexamen onderzoek \& ontwerpen in de tweede fase. Enschede: SLO. Retrieved from https://slo.nl/ sectoren/havo-vwo/onderzoeken/bovenbouw/@ 4277/handreiking-5/

SLO (2017). Vaksectie Natuur \& techniek. Natuurwetenschappelijke vakken. Vakspecifieke trendanalyse [Department of Nature \& technology. Natural science subjects. Subject-specific trend analysis]. Retrieved from https://slo.nl/@9257/ vta2017/

Stichting Technasium (2020) Onderzoek \& Ontwerpen. Retrieved from https://www.technasium.nl/ content/onderzoek-ontwerpen

Tsai, C. C. (2004). Conceptions of learning science among high school students in Taiwan: A phenomenographic analysis. International Journal of Science Education, 26(14), 1733-1750. https:/ / doi.org/10.1080/0950069042000230776

Van Rossum, E. J., \& Schenk, S. M. (1984). The relationship between learning conception, study strategy and learning outcome. British Journal of Educational Psychology, 54(1), 73-83. https:/ / doi.org /10.1111/j.2044-8279.1984.tb00846.x 
Van Rossum, E. J., Deijkers, R., \&Hamer, R. (1985). Students' learning conceptions and their interpretation of significant educational concepts. Higher Education, 14(6), 617-641. https://doi.org/ 10.1007/BF00136501

Vincenti, W. G. (1990). What engineers know and how they know it (Vol. 141). Baltimore: Johns Hopkins University Press.

Williams, J. (2018). Technology Education: History of Research. In M. de Vries (eds.), Handbook of
Technology Education. Cham, Switerzland: Springer International Publishing.

Zhou, Z. (2007) Exploration of technology curriculum in French high schools [in Chinese]. Curriculum, teaching material and method, 07, 93-96.

Zwart, S. D. (2009). Introduction to part IV. In A. W. M. Meijers (Ed.), Philosophy of technology and engineering sciences (pp. 633-636). Amsterdam: North-Holland. https://doi.org/10.1016/B978-0444-51667-1.50027-6

\section{http://www.ejmste.com}

